Edvard

Konrad

Filozofska

fakulteta

v Ljubljani

\section{CELOVITO OBVLADOVANJE KAKOVOSTI V IZOBRAŽEVALNIH ORGANIZACIJAH}

$P_{\text {in }}$ se $\mathrm{v}$ drugi polovici prejšnjega stoletja razvijala več desetletij in se kulminirala $\mathrm{v}$ gibanje za celovito obvladovanje kakovosti TQM (Total Quality Management). Gre za poslovno filo-

Eden izmed pionirjev pristopa TQM E. Deming (1982) je na podlagi dolgoletne prakse strnil osnovne ideje tega pristopa v $14 \gg$ zapovedik:

1. Ustvari cilje za izboljšanje.

2. Sprejmi novo filozofijo vodenja.

3. Ne zanašaj se na množično kontrolo.

4. Ne ocenjuj dela samo glede na cene.

5. Nenehno izbol:š̌uj sistem proizvolnje in zmanjšuj stroške.

6. Uvajaj sodobne metode treninga pri delu.

7. Uvajaj sodobne metode vodenja.

8. Uě̉nkovito delaj za organizacijo.

9. Odpravi ovire med oddelki.

10. Odpravi numeriěne cilje, posterje in slogane, ki ne zagotavljajo metode.

11. Odpravi delovne standarde, ki predpisujejo metode.

12. Odpravi ovire, ki posamezniku onemogočajo, da bil ponosen na svoje delo.

13. Uvedi intenzivne programe izobraževanja in lastnega izpopolnjevanja.

14. Ustvari vodstveno strukturo, ki bo gonilo za navedenih 13 tock. zofijo, ki prodira v vse organizacije, ki se ukvarjajo s proizvodnjo dobrin in storitvami, torej tudi v izobraževalne organizacije. TQM je sistematičen praktičen managerski pristop, ki zahteva številne spremembe v procesih organiziranja, strateških prioritetah in v prepričanju, stališčih ter vedenju posameznikov $\mathrm{z}$ namenom dosegati večjo kakovost. To ni natančno opredeljena metoda, temveč amorfna filozofija, ki jo sproti oblikujejo managerji, konzultanti in raziskovalci, ki se pri svojem delu opirajo na lastno razumevanje principov TQM.

Omenjene zapovedi, ki jih nekateri na kratko imenujejo tudi teorija D, zajemajo principe za izboljševanje prakse managementa za doseganje večje kakovosti. Ti principi so sicer uporabni pri delu konzultantov, vendar njihova teoretična podlaga še daleč ni dovolj jasna. Brez nje jih namreč težko prenašamo v različne situacije. Kot so pokazale analize Andersona in sodelavcev (1994) je v ozadju Demingovih principov sedem teoretičnih pojmov (prikazani so na sliki). Svoje ugotovitve so omenjeni avtorji povzeli takole: učinkovitost Demingovega pristopa izhaja iz prizadevanj vodstva ustvariti organizacijo, v kateri prevladujeta takšno sodelovanje in učenje, ki podpirata uvajanje različnih načinov upravljanja procesov, ki zagotavljajo nenehno izpopol- 
Slika: Teoretična podlaga Demingovega pristopa k zagotavljanju kakovosti (po: Anderson in sod., 1994)

\section{Teoretična podlaga Demingove teorije upravljanja kakovosti}

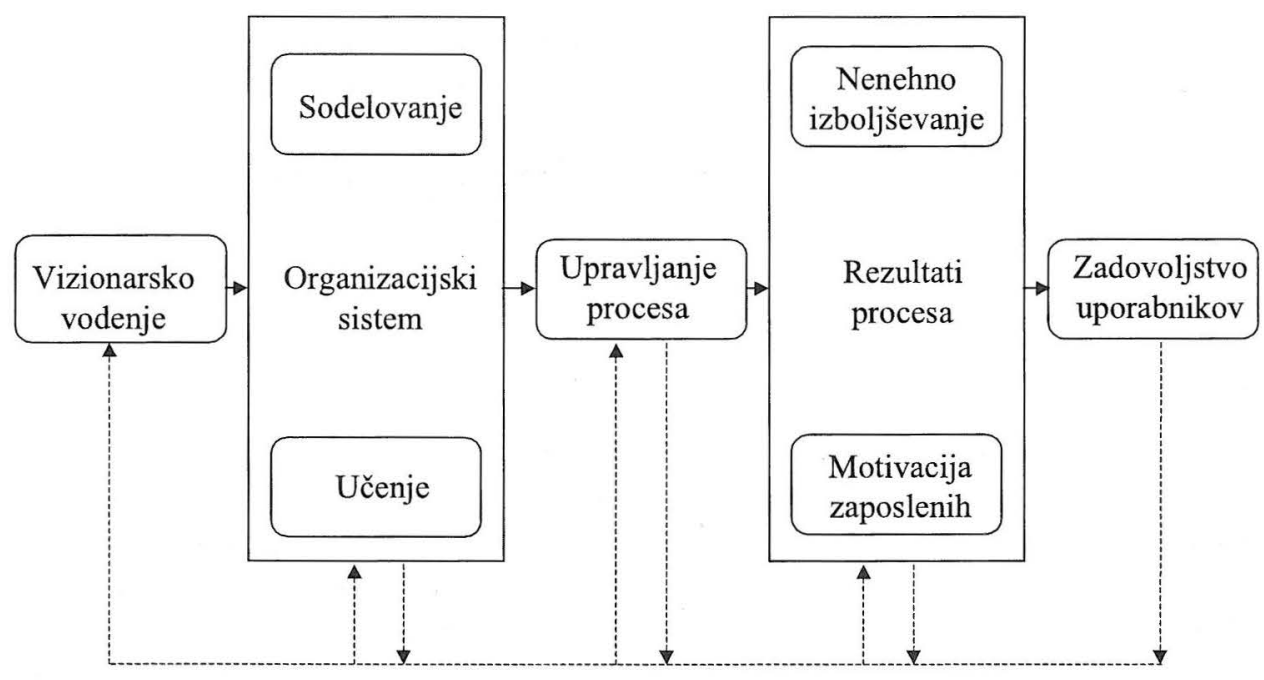

njevanje dela, procesov ter proizvodov na eni strani in motivacijo zaposlenih na drugi strani, s tem pa tudi doseganje zadovoljstva uporabnikov. Omenjeni teoretični pojmi nam omogočajo kreativnejše razmišljanje o problemih kakovosti na področju, ki se precej razlikuje od industrijske proizvodnje, $v$ našem primeru pri izobraževanju odraslih. Ker je problem kakovosti na tem področju očitno precej zapleten, lahko $\mathrm{v}$ tem prispevku nakažemo le nekatere njegove vidike.

\section{POJEM UPORABNIKA PRI IZOBRAŽEVANJU}

Podobno kot na drugih področjih je treba tudi pri izobraževanju začeti z zadovoljstvom uporabnikov. V proizvodnji je uporabnik izdelkov in storitev več ali manj razviden. TQM zahteva v tem primeru večje upoštevanje uporabnikovih izkušenj in pogledov. Ta premik se sicer zdi enostaven, vendar se je izkazalo, da njegova dosledna realizacija vnaša v organizacijo revolucionarne spremembe. Med izdelkom in uporabnikom je običajno precej dolga pot. Izkaže se, da upoštevanje uporabnikovih želja zahteva spremembe $\mathrm{v}$ celotni prodajni in proizvodni verigi, od načrtovanja izdelka in nabave surovin. Tako pridemo do predpostavke, da ima vsak zaposleni »uporabnika«, katerega želje moramo upoštevati, če hočemo, da bo končni uporabnik zadovoljen. To idejo so na proizvodnem področju uspešno realizirali na Japonskem (Young, 1992).

Na področju izobraževanja je pojem uporabnika še bolj zapleten. Ker se marsikomu sploh upira, da bi na tem področju razmišljal v okviru tržnih pojmov, kot je zadovoljstvo uporabnika, je v tem primeru ustreznejši pojem interesnih strank, konstituentov ali deležnikov (stakeholderjev). Priznati je treba, da imajo na področju izobraževanja svoje interese različni deležniki: država, delovne organizacije, starši ali družine udeležencev izobraževanja, izvajalci izobraževanja in seveda navsezadnje tudi učenci ali subjekti izobraže- 


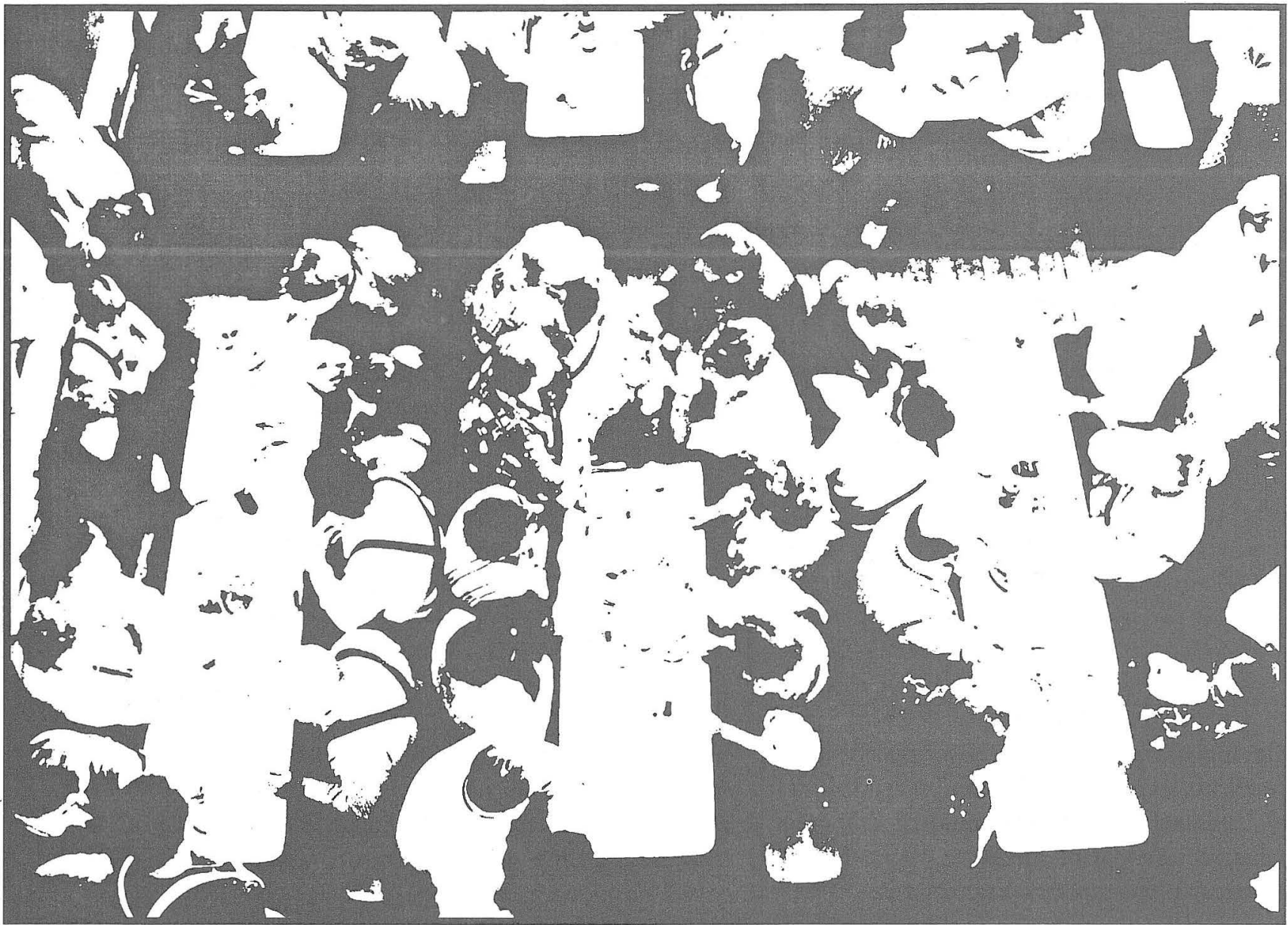

vanja. Jasno je tudi, da so njihovi interesi večkrat neusklajeni ali si celo nasprotujejo. Očitno je, da v tem primeru ni mogoče enostavno odločiti, katero zadovoljstvo naj bo merilo kakovosti izobraževalnih storitev. Dogaja se in se bo še dogajalo, da bodo nekateri deležniki vsiljevali drugim svoja merila kakovosti. Vendar postaja vse jasneje, da brez upoštevanja drugih deležnikov nikomur ne bo uspelo napredovati z vidika doseganja celovite kakovosti.

Naveličani teh sporov bodo nekateri morda videli izhod $\mathrm{v}$ tem, da bi opredelitev merila kakovosti prepustili znanstveni ali strokovni presoji. Zgovoren primer je eksterno preverjanje znanja $v$ šoli. Izkušnje iz industrije ka- žejo, da tako problema kakovosti ne bomo rešili. Iz lastnih izkušenj vemo, da ljudje izdelkov, ki so bili izdelani v skladu s standardi JUS, niso prav radi kupovali, če so imeli na voljo druge možnosti. Tudi v prihodnje ni pričakovati, da bodo kupovali izdelke samo zato, ker bodo ustrezali standardom ISO. Seveda to še ne pomeni, da tehničnih standardov sploh ne potrebujemo, temveč to, da pojem kakovosti presega pojem tehničnih standardov. Ni čudno, da je Deming nenehno opozarjal, da morajo organizacije opustiti različne kvantifikacije, ki so večkrat v škodo kakovosti, in dajati več poudarka sodelovanju. Izkušnje iz industrije kažejo, da je to teže kot pa organizirati oddelke za kontrolo kakovosti (ali komisije za evalvacije). 


\section{MOTIVACIJA UDELEŽENCEV IZOBRAŽEVANJA}

Posebno pozornost $\mathrm{v}$ izobraževalnem kontekstu zasluži problematika motivacije udeležencev. V proizvodnih razmerah o motivaciji delavcev še vedno razmišljajo z vidika plače, v izobraževalni panogi pa je očitno, da z učitelji, ki so motivirani samo $\mathrm{z}$ denarjem, ne bomo dosegli izobraževalnih rezultatov. Pravimo, da šola »stoji in pade « z učiteljem, pri čemer seveda mislimo sposobne in intrinzično motivirane učiteljice in učitelje. Na žalost pa je tudi res, da v praksi srečamo vrsto dejavnikov, ki rušijo intrinzično motivacijo in ne omogočajo ljudem tistega, kar Deming imenuje ponos $\mathrm{v}$ zvezi $\mathrm{z}$ uspešno opravljenim delom. To kaže, da se moramo pri zagotavljanju večje motivacije lotiti reševanja paradoksalnih problemov: vemo, da brez ustrezne plače ni mogoče zagotoviti zadovoljstva $z$ delom, po drugi strani pa tudi to, da s samo plačo ni mogoče zagotoviti intrinzične motiviranosti za delo. Če odmislimo plačo, je vendar treba priznati, da ima vloga učitelja kljub vsemu več potencialnih dejavnikov za razvoj pozitivne motivacije kot vloga proizvodnega delavca.

Problem je tudi motivacija tako imenovanih »učencev«. Slabo motiviran učenec se ne more kakovostno učiti. Tudi $\mathrm{v}$ tem primeru zunanji posegi delovne organizacije, učiteljev in staršev večkrat ne dajo pričakovanih rezultatov. Star pregovor pravi, da konja lahko pripelješ do vode, ne moreš pa ga prisiliti, da pije. Tako pridemo do spoznanja, da je za svojo motivacijo odgovoren vsak učenec sam. Te odgovornosti se morda na določeni razvojni stopnji ne zaveda v celoti. Prizadevanja drugih lahko njegovo motivacijo povečujejo ali zavirajo, ne pa determinirajo. Ne smemo tudi pozabiti, da določene okoliščine rušijo motivacijo za učenje tudi pri intrinzično motiviranih učencih (na primer preobremenjeni urniki, slabe prostorske in ekološke razmere) ali delavcih. Povečati motivacijo za učenje, ne samo v šoli, temveč tudi po končani šoli, je pravzaprav eden pomembnih izobraževalnih ciljev.

\section{IZBOLJŠEVANJE PROCESOV IZOBRAŽEVANIA}

Pri izboljševanju upravljanja procesov TQM zahteva uvajanje postopkov, ki zadevajo različne kombinacije tehničnih in človeških vidikov dela z namenom izboljšanja proizvodnih rezultatov. Na primer: uvajanje statistične kontrole kakovosti temelji na podatkih o inputih in outputih določenega tehnološke-

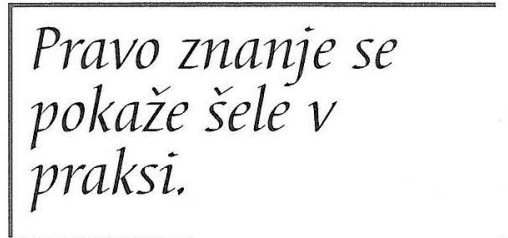
ga procesa, ki mora biti podprto $\mathrm{z}$ znanjem delavca o statističnih indikatorjih in njihovi interpretaciji. Na področju izobraževanja gre seveda za postopke, s katerimi je mogoče povečati kakovost znanja udeležencev izobraževanja. Inoviranje izobraževalnih metod je sicer ena izmed pomembnih nalog učitelja. Pri tem se učitelji opirajo na znanstvena spoznanja s pedagoškega področja. Te inovativne procese bi nedvomno prispevala tudi spoznanja, ki se oblikujejo v proizvodnih organizacijah kot pojem management znanja (knowledge management). Težišče proizvodnega dela se namreč premika k procesom, ki so povezani z znanjem. Management znanja pa je usmerjen k procesom, ki so povezani s kreiranjem, diseminacijo in izrabo znanja.

Temeljno vprašanje, ki ga je sprožil pristop management znanja in ki je pomembno tudi za področje izobraževanja, je, kaj je pravzaprav znanje. Vprašanje je sicer filozofsko naravnano, vendar je treba nanj odgovoriti tako, da je odgovor uporaben v praksi. Ena izmed mnogih takšnih opredelitev je opredelitev Freda Kofmana: znanje je zmožnost za učinkovito delovanje na področjih, kjer učinkovitost presoja skupina praktikov ali stro- 
kovnjakov. Na področju izobraževanja sicer že dolgo vemo, da golo »šolsko znanje « ni tisto, k čemur stremimo, in da se pravo znanje učencev izkaže šele v praksi. Vsekakor je treba inovirati šolski proces tako, da bo ta prenos čim učinkovitejši. Po analogiji s proizvodnjo bi kazalo tudi več razmišljati o tem, kako meriti učinkovitost znanja $\mathrm{v}$ praksi. Problem je precej zapleten, če upoštevamo, da ima znanje več ravni, ki se med seboj prepletajo: podatki, informacije, znanje v ožjem pomenu in modrost. Pomembne posledice ima tudi razlikovanje med eksplicitnim in tacitnim znanjem. Šole so nagnjene k poudarjanju eksplicitnega znanja, v praksi pa ima pomembnejšo vlogo tacitno znanje. $\mathrm{V}$ izobraževalnem procesu bi morali posvetiti več pozornosti procesom prehajanja iz ene $\mathrm{v}$ drugo obliko znanja (Nonaka \& Takeuchi, 1995).

\section{POJEM KAKOVOST UČENJA}

Naslednje vprašanje, ki ga je sprožil pristop managementa znanja in ki je pomembno za področje izobraževanja, zadeva naravo učenja. Probleme učenja obravnavajo različne psihološke teorije. Management znanja s praktičnega vidika opredeljuje učenje kot povečevanje ali razširitev znanja, kar pomeni

V izobraževalnih organizacijah se ne učijo samo učenci, temveč tudi učitelji. Ena izmed pomembnih idej TMQ je nenehno osebno izpopolnjevanje in motiviranost delavcev za povečevanje kakovosti izobraŽevanja. Pogoj za to je ustrezna sistemska organiziranost, ki te procese spodbuja. Ta organiziranost se razlikuje od doslej prevladujočega hierarhičnega sistema po tem, da bolj poudarja tiste principe učeče se organizacije (Senge, 1990), ki zadevajo medsebojno sodelovanje in timsko delo. možnosti za učinkovito akcijo. Učenje je torej nekaj, kar proizvaja vrednost. Psihološke teorije učenja so večinoma usmerjene $\mathrm{k}$ procesom, ki potekajo pri posamezniku. V proizvodnji so se oblikovali pojmi, ki prenašajo procese učenja na skupino ali organizacijo: organizacijsko učenje in učeča se organizacija. Očitno je, da se s tem spreminja klasično pozitivistično pojmovanje učenja kot osvajanja mentalnih reprezentacij, ki jih uporabimo pri delu. Vse bolj se poudarjajo tisti vidiki znanja in učenja, ki omogočajo sprotno reševanje proizvodnih problemov - tako imenovani pristop »just in time $\ll-z$ medsebojnim sodelovanjem zainteresiranih.

\section{VODENJE V IZOBRAŽEVALNIH ORGANIZACIJAH}

Treba se je zavedati, da omenjeni procesi zagotavljanja večje kakovosti v organizacijah ne potekajo avtomatično, temveč potrebujejo določen zagon. Ta zagon pa je ustrezno vodenje. Izkušnje so pokazale, da ne more priti do večjih premikov na področju kakovosti, če kakovost ni sestavni del vizije ali poslanstva managementa. Izhajajoč iz te vizije, lahko management uvaja različne organizacijske strukture in procese, s katerimi se lahko ta vizija uresničuje. Deming večkrat poudarja, da povečanja kakovosti ni mogoče pričakovati le z mehansko uporabo sodobnejših metod, temveč z izboljšanjem načina vodenja. Opozarja tudi, da so nekatere metode managementa kontraprodaktivne in $\mathrm{v}$ škodo kakovosti. V zvezi z načini vodenja bi kazalo opozoriti na razlikovanje med transakcijskim in transformacijskim vodenjem (Burns, 1978). Pri obeh oblikah vodja vpliva na prepričanja in vrednote sodelavcev. Pri transakcijskem vodenju je vodja usmerjen predvsem $\mathrm{k}$ določanju delovnih nalog sodelavcev, razlagi načinov za njihovo izvajanje in pojasnjevanju posledic, ki izvirajo iz uspešno ali neuspešno

medisebojno sodelovanje in timsko delo. 
opravljenega dela. Pri transformacijskem načinu vodenja pa vodja vpliva na razvijanje občutka lastne kompetentnosti pri sodelavcih in na njihove vrednostne usmeritve. $\mathrm{V}$ delovni situaciji vedno obstajata oba načina vodenja. Vendar TQM poudarja izreden pomen transformacijskega oziroma inspiracijskega vodenja. Če zaposleni ne bodo osebno prepričani o pomenu kakovosti in kakovostnega dela, ne bodo našli osebne izpolnitve, $\mathrm{z}$ metodo »palice in korenčka« pa ne bomo dosegli pomembnih premikov $\mathrm{z}$ vidika večje kakovosti.

Iz tega je razvidno, da ima celovito obvladovanje kakovosti v izobraževalnih organizacijah zelo dolgoročne implikacije. Spencer (1994) meni, da je gibanje TQM spodbudilo organizacije, da ponovno razmislijo o nekaterih splošnih temah in se do njih opredelijo, to so:

- organizacijski cilji,

- definicija kakovosti,

- vloga in narava okolja,

- vloga managementa,

- vloga zaposlenih,

- racionalnost organizacijske strukture,

- pogledi na razvoj in spremembe.

Ukvarjanje s temi temami je seveda pomembno tudi za izobraževalne organizacije. Pri tem ne smemo pričakovati, da bomo na podlagi različnih tehničnih in metodoloških postopkov odgovorili na vprašanja, ki imajo širši kulturni pomen in na katera številne organizacije (še) nimajo zadovoljivega odgovora. Nekatere ideje, ki so se razvile $v$ zvezi z izdelki in storitvami, so zanimive tudi za izobraževalno področje. Seveda pa zahteva njihovo prenašanje na področje kakovosti izobraževalnih storitev še precej kreativnega in raziskovalnega dela. Vsekakor se lahko od tega, kako v drugih okoljih rešujejo probleme zagotavljanja večje kakovosti, marsikaj naučimo.

\section{LITERATURA}

Anderson, C. J., Runjtusanathan, M. \& Schroeder, G. R. (1994): A theory of quality management underlying the Deming management method. Academy of Management Review, 19, 3, 472-509.

Burns, J. M. (1978): Leadership. New York: Harper \& Row.

Deming, W. E. (1982): Quality, productivity and competetive position. Cambridge Ma.: Center for Advanced Engineering Study, MTI.

Nonaka, I. \& Takeuchi, H. (1995): The knowledge-creating company. New York: Oxford University Press.

Senge, P. M. (1990): The fifth discipline. New York: Doubleday Currency.

Spencer, A. B. (1994): Models of organization and total quality management: A comparison nad critical evaluation. Academy of Management Review, 19, 3, 446-471.

Young S. M. (1992): A framework for successful adoption and performance of Japanese manufacturing practices in the United States. Academy of Management Review, 17, 4, 677-700. 